\title{
Electrochemical and Morphology Study of the BDD/Ti Electrodes with Different Doping Levels
}

Suellen A. Alves, Fernanda L. Migliorini, Mauricio R. Baldan, Neidenei G. Ferreira and Marcos R. Lanza

ECS Trans. 2012, Volume 43, Issue 1, Pages 191-197.

doi: $10.1149 / 1.4704957$

Email alerting

Receive free email alerts when new articles cite this article - sign up in the service box at the top right corner of the article or click here

To subscribe to ECS Transactions go to: http://ecst.ecsdl.org/subscriptions

(C) 2012 ECS - The Electrochemical Society 


\title{
Electrochemical and Morphology Study of the BDD/Ti Electrodes with Different Doping Levels
}

\author{
S.A. Alves ${ }^{a}$, F.L. Migliorini ${ }^{b}$, M.R. Baldan ${ }^{b}$, N.G. Ferreira ${ }^{b}$, and M.R.V. Lanza ${ }^{a}$ \\ a Instituto de Química de São Carlos, Universidade de São Paulo, São Carlos, Brasil \\ ${ }^{\mathrm{b}}$ Instituto Nacional de Pesquisas Espaciais, São José dos Campos, Brasil.
}

Boron-doped diamond (BDD) electrodes have shown characteristics that differ from other conventional electrodes, and that make them an excellent electrode in the electroanalysis, in the electrosynthesis and also in the treatment of wastewater with organic compounds. In this work, two different electrodes doped with $(2,000$ and 15,000 $\mathrm{ppm})$ were characterized by Raman Spectroscopy and by Scanning electron Microscopy (SEM). In addition, they were characterized electrochemically by cyclic voltammetry. The electroactive area was estimated according to Cottrell's equation before and after the anodic and the cathodic treatment. From the results, it was observed that the electrodes have a similar behavior in the morphology and in the homogeneity of the films. The large potential window was confirmed for both electrodes $(2.5 \mathrm{~V} v s \mathrm{Ag} / \mathrm{AgCl})$ and for the less doped electrode was obtained a larger area without any treatment while for the more doped electrode, the major area was obtained after the cathodic treatment.

\section{Introduction}

Boron-doped diamond electrodes (BDD) are relatively new, which make them different from the conventional materials. Their electrochemical properties began to be studied in the 80 's by Pleskov et al and several studies have been performed to understand their behavior [1]. Several features make the BDD electrode a promising material due to its very wide working potential window in aqueous electrolytes, low background current, high chemical inertness and dimensional stability [2]. Because of these features the BDD electrodes have been successfully used in different areas such as electrosynthesis, water treatment [3][4][5] and electroanalysis [6][7].

The growth method CVD (chemical vapor deposition) is based on the gas-phase decomposition above a solid surface, to reactive species, which causes deposition onto that surface leading to an uniform thin film. The film quality and morphology depend on the growth conditions. Most of the CVD diamond films have been grown on silicon wafers but another substrate may be used such as: niobium and titanium.

In order to obtain an increase in the conductivity, the diamond is doped since natural diamond is insulating, consequently several dopants can be used, such as, boron (p-type doping) which is the most used. Several doping levels can be incorporated: for the intermediate doping (about $10^{8}$ boron atoms $\mathrm{cm}^{-3}$ ) the electrode is considered a semiconductor while for high doping level (about $10^{20}$ to $10^{21}$ boron atoms $\mathrm{cm}^{-3}$ ), the 
electrode presents semimetalic behavior with resistivity of approximately $10^{-3} \Omega \mathrm{cm}[8]$ [9].

One of the major problems in the understanding of these electrodes is the estimate of the electroactive area, since its topology may change from a pyramidal to a cauliflower structure which is attributed to the renucleation process. The electrodes present a surface that is not homogeneous and may contain different levels of roughness. Therefore, it becomes necessary to determine a method to estimate the electroactive area and the interference of the electrochemical surface pre-treatments.

Studies have been carried out to elucidate the electrochemical behavior regarding the surface of such electrodes. Girard et al reported a modification of the electrochemical behavior for the BDD surface after the preconditioning. The preconditioning can affect the physical and the chemical properties of the diamond surface. The electrode "asdeposited" has a hydrogen termination with negative electron affinity, high conductivity and it presents a hydrophobic character. After the anodic treatment, the surface displays an oxygen-termination with positive electron affinity, low conductivity and a hydrophilic character [10]. Suffredini et al studied the effect of cathodic pretreatment in the BDD electrodes. The authors observed that the electrochemical response is directly affected by pretreatment, in the presence of $\left[\mathrm{Fe}(\mathrm{CN})_{6}\right]^{3+/ 2+}$ solution the electrodes presented a reversible response after the cathodic polarization, while the anodic polarization distorted such response [11].

This work presents a morphological and a electrochemical characterization of Ti/BDD with different doping levels (2,000 and 15,000 ppm, relationship B/C) by using techniques such as Scanning Electron Microscopy (SEM), Raman Spectroscopy, Cyclic Voltammetry (CV) and chronoamperometry. The latter was used to determine the electroactive area according to Cottrell's equation. Moreover, the effects of the anodic and the cathodic pretreatment to the electroactive area were studied.

\section{Experimental Procedure}

\section{Construction of electrodes}

The BDD electrodes were grown on Ti substrates by using the chemical vapor deposition (CVD) technique. The deposition of diamond on titanium has a singular characteristic attributed to the strong stress formation between the film and the substrate, which arises from extrinsic and intrinsic factors. In this sense, some pretreatments of the substrate surface are required to decrease the stress and to increase the nucleation rate [22-24].In addiction, the mechanical incision is effective to increase the titanium surface area and roughness besides improving the mechanical anchoring of the film. This incision can be obtained, for example, in air abrasion with glass beads, or by scratching the surface with an abrasive agent such as diamond paste. The treated surface ensures the best adhesion of the diamond coating due to its higher effective area for the film deposition. The BDD/Ti with dimensions of $25 \times 25 \times 0.5 \mathrm{~mm}$ was grown from a standard gas mixture consisting of $99 \%$ of $\mathrm{H}_{2}$ and $1 \%$ of $\mathrm{CH}_{4}$. The temperature and pressure inside the chamber reactor were kept at $650{ }^{\circ} \mathrm{C}$ and 50 Torr, respectively for $7 \mathrm{~h}$. The doping control was obtained from an additional $\mathrm{H}_{2}$ gas flux passing through a bubbler containing a solution of $\mathrm{B}_{2} \mathrm{O}_{3}$ dissolved in $\mathrm{CH}_{3} \mathrm{OH}$ with the $\mathrm{B} / \mathrm{C}$ ratio of $2,000 \mathrm{ppm}\left(\mathrm{E}_{1}\right)$ and $15,000 \mathrm{ppm}\left(\mathrm{E}_{2}\right)$. This additional hydrogen flow into the reactor was controlled by a rotameter which was maintained at $40 \mathrm{sccm}$ for both experiments. 


\section{Electrodes characterization}

The top view SEM images of BDD films were obtained from a Jeol equipment JSM5310. The quality of BDD films was analyzed from Micro-Raman spectra recorded by a Renishaw microscope system 2000 in backscattering configuration at room temperature employing $514.5 \mathrm{~nm}$ argon-ion laser.

The BDD/Ti working electrodes $\left(4.15 \mathrm{~cm}^{2}\right.$ of the geometric area) were located at the bottom of the cell. A platinum screen, $2 \mathrm{~cm}$ in diameter, was used as a counter electrode and a commercial $\mathrm{Ag} / \mathrm{AgCl}$ electrode $\left(3.0 \mathrm{~mol} \mathrm{~L}^{-1} \mathrm{KCl}\right.$ solution) was used as the reference electrode. It was used a potentiostat/galvanostat AUTOLAB model PGSTAT 302 (Eco Chimie), controlled by the GPES software. The potential window was determined with $\mathrm{H}_{2} \mathrm{SO}_{4} 0.1 \mathrm{~mol} \mathrm{~L}^{-1}$ suport electrolyte.

The study of active area of the electrodes was carried out by using choronoamperometry method. The active area was evaluated with solution of $\mathrm{H}_{2} \mathrm{SO}_{4} 0.1$ mol L${ }^{-1}$ and $1 \mathrm{mmol} \mathrm{L}^{-1} \mathrm{~K}_{3}\left[\mathrm{Fe}(\mathrm{CN})_{6}\right]$ previously saturated with $\mathrm{N}_{2}$ during 5 minutes.

\section{Results and discussion}

\section{Morphology and structural characterization}

The morpholical study of the diamond films with different doping levels was obtained by SEM images (inset Figure 1). The homogeneous films covering the entire substrates could be observed. The cracks or delaminations of the films were not observed because the film were very adherent. This is very important since the diamond growth on the $\mathrm{Ti}$ substrates presents the following problems: a difference between the thermal expansion coefficients of the Ti substrate and the diamond film and the possible formation of intermediate phases such as hydrides and titanium carbides [12].
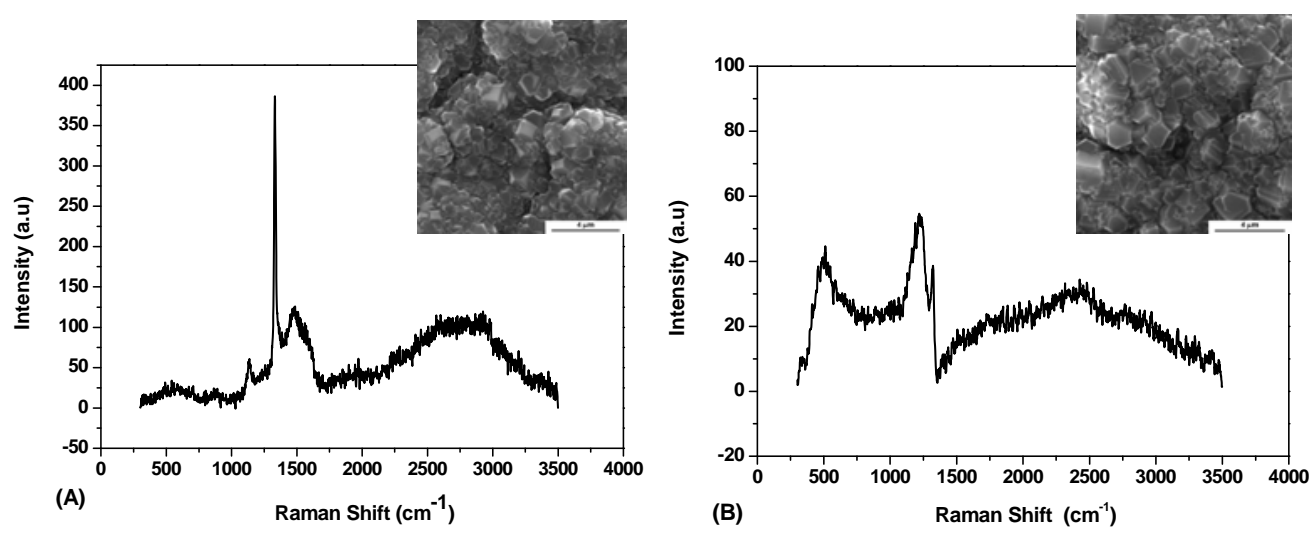

Figure 1. Raman spectra of (A) electrode $E_{1}$ and (B) electrode $E_{2}$; BDD films, inset Scanning electron micrographs

By using Raman spectroscopy, it was possible to analyse the composition and the quality of the BDD films. The presence of a Raman peak at around $1,332 \mathrm{~cm}^{-1}$ was verified for the electrode $E_{1}$, which corresponds to the diamond first-order phonon vibration. However, for the electrode $\mathrm{E}_{2}$ the intensity of the peak was lower. The emergent band at $1,200 \mathrm{~cm}^{-1}$, which is characteristic of the boron doped diamond films is attributed to the induced disorder in the diamond structure due to the boron incorporation. 
This band increases significantly by increasing the doping level which is associated to a drastic reduction in the diamond peak [13][14]. The band at around $1,580 \mathrm{~cm}^{-1}$ is attributed to $\mathrm{G}$ band, graphitic phases, and this band is observed in the electrode $\mathrm{E}_{2}$. The presence of a band at around $500 \mathrm{~cm}^{-1}$ is also observed, which is attributed to the vibration of boron pairs in the diamond lattice. By comparing the quality of the two electrodes, the electrode $\mathrm{E}_{2}$ showed a better quality which was confirmed by the complete absence of the sharp peak at around $1,580 \mathrm{~cm}^{-1}$.As the $\mathrm{sp}^{2}$ phase is found at the grain boundary, the largest grains of the $\mathrm{E}_{2}$ led to the lowest contribution of the $\mathrm{sp}^{2}$ phase when the same area is exposed to the Raman laser for both electrodes. In addition, the boron content in diamond reaches, which was $2,94 \times 10^{20} \mathrm{~cm}^{-3}$ and 7,09 $\times 10^{20} \mathrm{~cm}^{-3}$ respectively to $\mathrm{E}_{1}$ and $\mathrm{E}_{2}$ was obtained.

\section{Electrochemical characterization}

The DDB electrodes have a wide potential window, and because of that, the detection of the redox reactions in certain potentials which are outside the range of the work potential for conventional electrodes, such as glass carbon, platinum and graphite. The BDD electrodes allowed the detection of compounds that have potentials more positive or negative without water interference or water electrolysis (Figure 2). The electrode $\mathrm{E}_{1}$ presents a wide potential window (about $2.5 \mathrm{~V}$ vs $\mathrm{Ag} / \mathrm{AgCl}$ ) and for the electrode $\mathrm{E}_{2}$ this behavior was similar. Besides, the difference in the doping level did not change the potentials of the oxygen and hydrogen evolution.

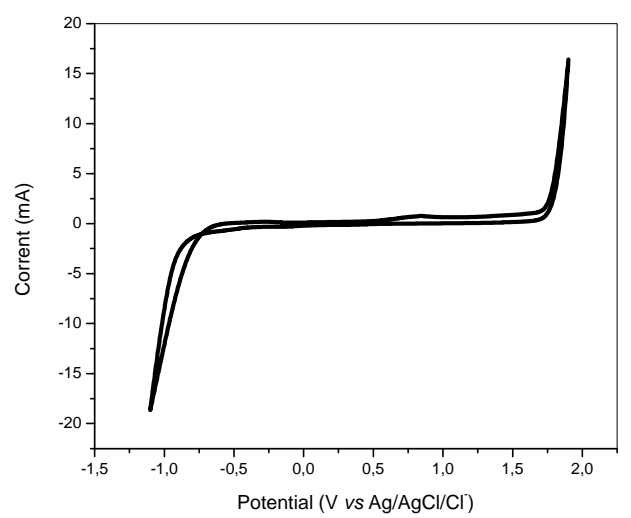

Figure 2. Cyclic voltammetry curve for the electrode $\mathrm{E}_{1}$ in $0.1 \mathrm{~mol} \mathrm{~L}^{-1} \mathrm{H}_{2} \mathrm{SO}_{4}$ at scan rate of $30 \mathrm{mV} \mathrm{s}^{-1}$.

The electrochemical behavior in $\mathrm{K}_{3}\left[\mathrm{Fe}(\mathrm{CN})_{6}\right]$ solution was carried out with cyclic voltammetry, and the cyclic voltammetry, without surface treatment (as received) and with surface treatment, can be seen in Figure 3 . The $\mathrm{E}_{2}$ electrode had a smaller $\Delta \mathrm{Ep}$ (190 $\mathrm{mV}$ ) compared to the $\mathrm{E}_{1}$ electrode $(280 \mathrm{mV})$. After the anodic treatment, both electrodes present an increase in the $\Delta \mathrm{Ep}$ when they are compared with their cyclic voltammetry without any treatment. The cathodic treatment provided a better electrochemical response, with an increase in the oxidation and in the reduction current peak. The peaks are well defined and can be assigned to the hydrogen superficial termination. 


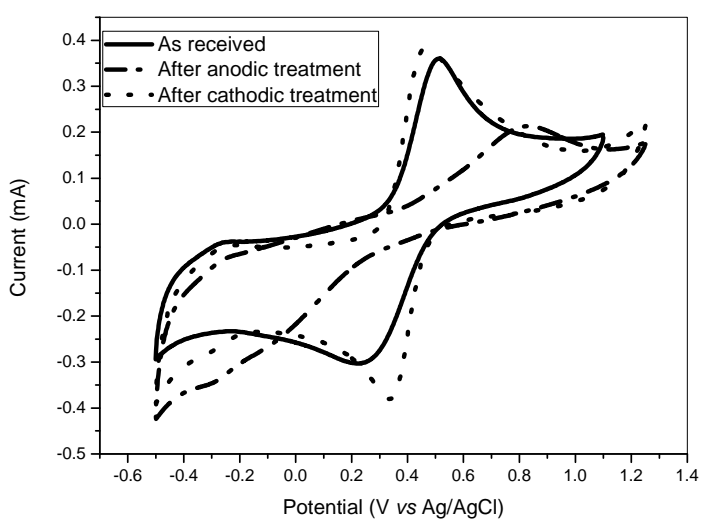

Figure 3. Cyclic voltammetry curves for the electrode $\mathrm{E}_{2}$ in $0.1 \mathrm{~mol} \mathrm{~L}^{-1} \mathrm{H}_{2} \mathrm{SO}_{4}$ and 1 mmol L ${ }^{-1} \mathrm{~K}_{3}\left[\mathrm{Fe}(\mathrm{CN})_{6}\right]$ at scan rate of $30 \mathrm{mV} \mathrm{s}^{-1}$ according to pretreatments.

In order to study the active area, the chromoamperometry method was carried out and the Cottrell's equation was applied. This method determines the current according to the Constant potential and it is correlated with the species concentration oxidized or reduced on the electrode surface (Equation 1):

$$
I_{t}=\frac{n F A C D_{0}^{1 / 2}}{\pi^{1 / 2} t^{1 / 2}}=B t^{-1 / 2}
$$

Where: $I_{t}$ is current (A), $\mathrm{n}$ is the number of electrons, $F$ is the Faraday constant $(96,485$ $\left.\mathrm{C} \mathrm{mol}^{-1}\right) A$ is the electrode area $\left(\mathrm{cm}^{2}\right), C$ is the concentration of reduced species $\left(\mathrm{mol} \mathrm{m}^{-3}\right)$, and $D_{0}$ is the difusion coefficient $\left(7.26 \times 10^{-6} \mathrm{~cm} \mathrm{~s}^{-1}\right)$. In chronoamperometry, two steppotentials are applied. In the region in which the first potential is applied presents no reaction with the electroactive species. The second potential is applied to the surface in which the reduced concentration species is zero [16]. The values obtained for the electrode areas are shown in Table 1.

TABLE I. Electroactive area of the BDD electrodes with different doping levels.

\begin{tabular}{ccc}
\hline & $\begin{array}{c}\mathbf{E}_{\mathbf{1}} \\
\left(\mathbf{c m}^{\mathbf{2}}\right)\end{array}$ & $\begin{array}{c}\mathbf{E}_{\mathbf{2}} \\
\left(\mathbf{c m}^{\mathbf{2}}\right)\end{array}$ \\
\hline As received & 9.97 & 10.38 \\
After anodic pretreatment & 5.26 & 8.28 \\
After cathodic pretreatment & 8.04 & 12.20 \\
\hline
\end{tabular}

The electrode $E_{2}$ presented a larger electroactive area without superficial pretreatment(as received). The electrode $\mathrm{E}_{2}$ presented a larger area after the cathodic treatment. For both electrodes the lower electroactive area was obtained after the anodic treatment. From the results, the electrode with a high doping level (E2) also presented a larger active area, and the cathodic treatment causes an improvement in the electrochemical response to the BDD electrodes in $\mathrm{K}_{3}\left[\mathrm{Fe}(\mathrm{CN})_{6}\right]$ solution. The electroative area is affected by the superficial termination of the BDD electrode because, depending on the termination, there is a higher conductivity. $\left[\mathrm{Fe}(\mathrm{CN})_{6}\right]^{2+/ 3+}$ is sensitive to the superficial termination on the the electrode surface. Therefore, it was possible to analyse this bahavior, where variations in the terminations and $\mathrm{C} \mathrm{sp}^{2}$ can be detected. 
The behavior of the electrodes in the $\mathrm{K}_{3}\left[\mathrm{Fe}(\mathrm{CN})_{6}\right]$ soluction at different scan ranges was studied.
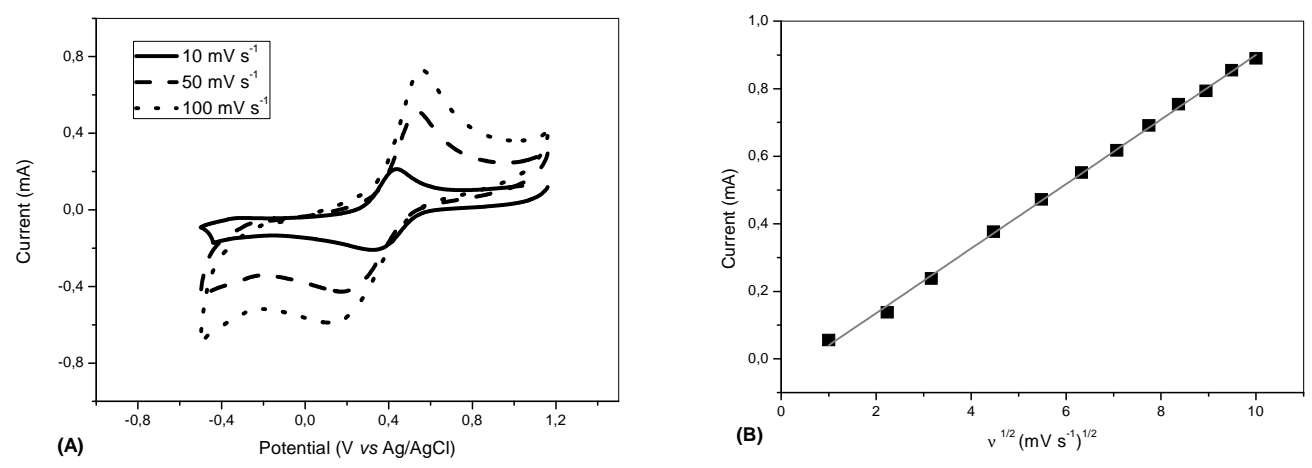

Figure 4. (A) Cyclic voltammetry curves for the electrode $\mathrm{E}_{1}$ in $0.1 \mathrm{~mol} \mathrm{~L}^{-1} \mathrm{H}_{2} \mathrm{SO}_{4}$ and 1 mmol L ${ }^{-1} \mathrm{~K}_{3}\left[\mathrm{Fe}(\mathrm{CN})_{6}\right]$ at different scan rates (B) The anodic current Peak vs square root of the scan rates

\section{Conclusions}

The quasi-reversible behavior was observed for both electrodes. In the scan range from 10 to $100 \mathrm{~cm} / \mathrm{s}^{-1}$ the $\Delta \mathrm{Ep}$ varied from $91 \mathrm{mV}$ to $418 \mathrm{mV}$. By increasing the scan rate, the anodic current peak increases and the linear behavior is observed as a function of the square root of scan rate characterizing a process controlled by diffusion.

The morphological and electrochemical characterizations of the electrodes studied allowed us to evaluate the difference in doping levels. Raman spectroscopy confirmed the formation of the diamond and the incorporation of boron in its crystal lattice. The electrodes showed a wide potential window $(2.5 \mathrm{~V} v s \mathrm{Ag} / \mathrm{AgCl})$ and the cyclic voltammograms obtained with $\mathrm{K}_{3}\left[\mathrm{Fe}(\mathrm{CN})_{6}\right]$ after the anodic treatment increased the $\Delta \mathrm{Ep}$ when compared with the electrode as received (no treatment) and the electrode after the cathodic treatment. It is observed that the cathodic treatment usually provides an increase in the electrode active area.

\section{Acknowledgments}

The authors gratefully acknowledge the financial support provided by FAPESP (2010/07525-3).

\section{References}

1. Y. Pleskov, E.S.S. A, L.L. Bouilov, B.V. Spitsyn, M.D. Krotova, J. Electroanal. Chem., 228, 19-27 (1987).

2. A. Fujishima, Y. Einaga, T.N. Rao, D.A. Tryk, Diamond electrochemistry, Elsevier B.V., Amsterdam (2005).

3. T. Panakoulias, P. Kalatzis, D. Kalderis, A. Katsaounis, Journal of Applied Electrochemistry., 40, 1759-1765 (2010).

4. L. Ciríaco, C. Anjo, J. Correia, M.J. Pacheco, A. Lopes, Electrochimica Acta., 54, 1464-1472 (2009). 
5. A.M. Polcaro, M. Mascia, S. Palmas, A. Vacca, Electrochim. Acta., 49, 649-656 (2004).

6. M.-jung Song, J.H. Kim, S.K. Lee, Microchimica Acta., 171, 249-255 (2010).

7. S. Szunerits, Y. Coffinier, E. Galopin, J. Brenner, R. Boukherroub, Electrochemistry Communications., 12, 438-441 (2010).

8. R.D. Cássia, M.D. Barros, M.C. Ribeiro, P.T. An-sumodjo, M. Sérgio, H.P. Serrano, I.D. Química, U.D.S. Paulo, A. Prof, L. Prestes, S.P. Sp, N.G. Ferreira, Quimica Nova., 28, 317-325 (2005).

9. M. Panizza, G. Cerisola, Processes, Electrochim. Acta., 51, 191-199 (2005).

10. H.A. Girard, N. Simon, D. Ballutaud, E.D.L. Rochefoucauld, A. Etcheberry, Diamond \& Related Materials, 16, 888 - 891 (2007).

11. H.B. Suffredini, V.A. Pedrosa, L. Codognoto, S.A.S. Machado, R.C. Rocha-filho, L.A. Avaca, Electrochimica Acta., 49, 4021-4026 (2004).

12. E. Buccioni, E. Braca, J.M. Kenny, M.L. Terranova, Diamond and Related Materials., 8, 17-24 (1999).

13. L.L.G. Silva, M.K. Franco, F. Yokaichiya, N.G. Ferreira, Diamond and Related Materials., 11, 153-159 (2002).

14. N.G. Ferreira, L.L.G. Silva, E.J. Corat, V.J. Trava-airoldi, Diamond and Related Materials., 11, 1523-1531 (2002).

15. Y. Fu, H. Du, C.Q. Sun, Thin Solid Films., 424, 107-114 (2003).

16. J.Wang, Analytical Electrochemistry, p. 60 ,Wiley., New York (2000). 